\title{
The Relationship Between Primary Care, Income Inequality, and Mortality in US States, 1980-1995
}

\author{
Leiyu Shi, DrPH, MBA, James Macinko, PhD, Barbara Starfield, MD, MPH,
} Jobn Wulu, PhD, Jerri Regan, MPA, and Robert Politzer, ScD

Objectives: This study tests the robustness of the relationships between primary care, income inequality, and population health by (1) assessing the relationship during 4 time periods-1980, 1985, 1990 and 1995; (2) examining the independent effect of components of the primary care physician supply;

(3) using 2 different measures of income inequality (Robin Hood index and Gini coefficient); and

(4) testing the robustness of the association by using 5-year time-lagged independent variables.

Data Sources/Study Setting: Data are derived from the Compressed Mortality Files, the US Department of Commerce and the Census Bureau, the National Center for Health Statistics, the Centers for Disease Control and Prevention, and the American Medical Association Physician Master File. The unit of analysis was the $50 \mathrm{US}$ states over a 15 -year period.

Study Design: Ecological, cross-sectional design for 4 selected years $(1980,1985,1990,1995)$, and incorporating 5-year time-lagged independent variables. The main outcome measure is age-

standardized, all-cause mortality per 100,000 population in all 50 US states in all 4 time periods.

Data Collection/Extraction Methods: The study used secondary data from publicly available data sets. The CDC WONDER/PC software was used to obtain mortality data and directly standardize them for age to the 1980 US population. Data used to calculate the income inequality measure came from the US census population and housing summary tapes for the years 1980 to 1995. Counts of the number of households that fell into each income interval along with the total aggregate income and the median household income were obtained for each state. The Gini coefficient for each state was calculated using software developed for this purpose.

Results: In weighted multivariate regressions, both contemporaneous and time-lagged income inequality measures (Gini coefficient, Robin Hood Index) were significantly associated with all-cause mortality $(P<.05$ for both measures for all time periods). Contemporaneous and time-lagged primary care physician-to-population ratios were significantly associated with lower all-cause mortality $(P<.05$ for all 4 time periods), whereas specialty care measures were associated with higher mortality $(P<.05$ for all time periods, except 1990, where $P<.1)$. Among primary care subspecialties, only family medicine was consistently associated with lower mortality $(P<.01$ for all time periods).

Conclusions: Enhancing primary care, particularly family medicine, even in states with high levels of income inequality, could lead to lower all-cause mortality in those states. (J Am Board Fam Pract 2003; 16:412-22.)

During the past decade, there has been an ongoing debate over the role of income inequality as a determinant of population health. ${ }^{1-4}$ The debate con-

Submitted, revised, 23 January 2003.

From the Johns Hopkins Bloomberg School of Public Health (LS, JM, BS) and the Bureau for Primary Care, Health Resources and Services Administration, United States Department of Health and Human Services (JW, JR, RP). Address reprint requests to: Leiyu Shi, DrPH, MBA, Associate Professor, Department of Health Policy and Management, Johns Hopkins Bloomberg School of Public Health, 624 N. Broadway, Room 406, Baltimore, MD 21205 (e-mail: lshi@jhsph.edu).

This study was funded by the Johns Hopkins Primary Care Policy Center and the Bureau of Primary Health Care, Health Resources and Services Administration. tinues, with evidence both supporting and refuting what has become known as the "relative income hypothesis"- the proposition that the greater the gap in income between the rich and poor in a given area, the worse the health status for the population of that area. Although international and crosscountry studies of the relative income hypothesis have resulted in conflicting conclusions, ${ }^{5,6}$ there is considerable evidence that, at least within the United States, income inequality is associated with poorer population health. ${ }^{7-9}$

There also has been increasing evidence of a link between primary care and improved health status. Both theoretical and empirical evidence for the 
association between primary care and improved health indicators exist. ${ }^{10}$ For example, Starfield, ${ }^{11}$ in comparing 11 Western industrialized nations in terms of the extent of their primary health service and the levels of health indicators including birth outcomes, life expectancy, and age-adjusted death rates, found that there was general concordance between the strength of primary care and the health indicators. These results were confirmed by a later study using 13 countries over several time periods. $^{12}$

Shi ${ }^{13-15}$ conducted a series of studies correlating sociodemographic and behavioral indicators with various health outcomes among the 50 states and the District of Columbia. Indicators included sociodemographic measures, lifestyle factors, and supply of medical services. These studies found that, among medical care variables, primary care was by far the most significant in its association with better health status, as reflected in lower overall mortality and lower death rates from heart diseases and cancer.

Although previous studies have examined the relationship between income inequality, primary care, and health outcomes, few published analyses have included all measures simultaneously. In one of the first studies of its kind, Shi and colleagues ${ }^{16}$ found that primary care had an independent and positive impact on health indicators and that in multivariate models controlling for demographic, income, and health system covariates, primary care actually reduced the magnitude of the deleterious impact of income inequality on health outcomes.

This study expands on earlier work that showed that primary care attenuated the effects of income inequality on population health within US states. It tests the robustness of the relationships between primary care, income inequality and population health during 4 selected years: 1980, 1985, 1990, and 1995. This study examines the independent effect of components of the primary care physician supply, as well as the supply of specialists. It compares the effect of 2 different income inequality measures (the Gini coefficient and the Robin Hood Index), and it tests the association of time-lagged independent variables with mortality over a 20 -year period.

\section{Methods}

\section{Data and Measures}

Data for this study came from the Compressed Mortality Files, the US Department of Commerce and the Census Bureau, ${ }^{17}$ the National Center for Health Statistics, ${ }^{18}$ and the Centers for Disease Control and Prevention (CDC). ${ }^{19}$ Physician data were obtained from the American Medical Association Physician Master File. ${ }^{20}$ Data were drawn from 1980, 1985, 1990, and 1995.

The outcome measure used was total all-cause mortality. Mortality is among the most commonly used health status indicators, especially in studies on income inequality and health.,19,21,22 It is significantly and inversely associated with life expectancy $(\mathrm{r}=-.90, P<.001$, based on 1990 US state data). The CDC Wonder/PC software ${ }^{23}$ was used to obtain mortality data and directly standardize them for age to the 1980 US population. Standardized data for each state are expressed as the number of deaths per 100,000 population.

Income distribution was measured by the Gini coefficient, a commonly used indicator of income inequality. The Gini coefficient is based on the Lorenz curve, a cumulative frequency curve that compares the distribution of a specific variable (eg, income) with the uniform distribution that represents equality. This equality distribution is represented by a diagonal line; the greater the deviation of the Lorenz curve from this line, the greater the inequality. Thus, the Lorenz curve is a mechanism to graphically represent the cumulative share of the total income accruing to successive income intervals. ${ }^{24}$ The Gini coefficient ranges from 0 to $1 ; 0$ represents perfect income equality and 1 total income inequality. The reduction of the Gini coefficient requires corresponding redistribution in income or wealth from the rich to the poor. Although the level of income inequalities is reflected in the value of the Gini coefficient itself (for example, a value very close to 0 will represent a low level of inequality), the interpretation of the coefficient is usually done in comparative terms, by contrasting the calculated value with that of other geographic units, population groups, etc. For example, a coefficient of 0.2 will represent a lower level of inequality than a coefficient of 0.4. For examples of Gini coefficient calculation, please refer to specific web sites (http://www.paho.org/English/SHA/ be_v22n1-Gini.htm).

Data used to calculate the income inequality measure came from the US census population and housing summary tapes for the years 1980 to 1995 . This file provides annual data on household income 
for 25 income intervals. Counts of the number of households that fall into each income interval along with the total aggregate income and the median household income were obtained for each state. The Gini coefficient was calculated using software developed by E. Welniak. ${ }^{25}$ We also used the Robin Hood index, another measure of income inequality that is less sensitive to highly skewed income distributions. ${ }^{26}$ Because both measures provided similar results, we generally only present results using the Gini coefficient.

Primary care physician specialties included family practice and general practice, general internal medicine, and general pediatrics. ${ }^{1,27}$ Family and general practice are often combined into a single group called family medicine. Thus, primary care physicians referred to doctors of medicine per 10,000 persons who were in active office-based patient care in family medicine, internal medicine, and pediatrics. For the sake of brevity, this variable is called primary care throughout this article. In the analysis, we compare the effect of this combined primary care measure with the independent effects of each primary care subspecialty.

We also evaluate the impact of specialty care on population health. Specialty care is defined as nonprimary care doctors of medicine per 10,000 persons (excluding physicians in residency training or osteopathic physicians) who were in active officebased patient care.

Analyses excluded other potential health determinants such as education, health insurance, racial/ ethnic minorities, and poverty for several reasons. First, previous studies using the same data sources and unit of analysis (US states) have already confirmed the relationship between income inequality and health while controlling for these covariates. ${ }^{16,28}$ Second, many covariates are highly correlated with the income inequality measure, so including them together in the same model could result in multicollinearity. For example, Blakely and Kawachi $^{29}$ found that using median household income in multiple regression models, including income inequality, can 'overcontrol' the association of income inequality with health outcomes. This could result in a greater chance of a type II error, because any absence of effect of income inequity might be explainable by its relationship with these other measures instead of its lack of relationship with the health outcome. ${ }^{30}$

\section{Design}

The present study was an ecologic study of the unmixed type; ie, our analyses correlated ecologic variables with an ecologic outcome. ${ }^{31}$ The unit of analysis was the 50 US states. Because we avoided making inferences about individual persons from grouped data, no cross-level bias occurred. ${ }^{31,32}$

One advantage of such an approach is the lower likelihood of random fluctuations in both numerators and denominators of mortality rates through geographic aggregation at the state level. Using state-level aggregate data also had the advantage of attenuating the likely "crossover" effect encountered when smaller units of analysis are used for measuring availability of medical care and mortality. ${ }^{19,33}$ The "crossover" effect refers to the likelihood that those who require specialized care may seek care in areas where that care is more available. However, patients are less likely to move across states than across smaller geographic units, such as counties or cities, to seek specialized care.

\section{Analysis}

In analyzing the data, we first looked at the correlation between contemporary and time-lagged income inequality, primary care and primary care subspecialties, and specialty care variables with health outcomes using Pearson's correlation coefficients at each 5-year period (1980, 1985, 1990, and 1995).

Multivariate models used weighted multiple regression. This procedure takes into account a weight (based on state population size) assigned to each observation that reflects the "relative amount of information" embodied in the observation. ${ }^{34}$ The multiple regression model was chosen because the variables included in the analysis were either interval or ratio measures and they seemed to be normally distributed. This technique allowed us to examine the association of any given independent variable on the dependent variable while holding all other independent variables constant.

Because the effects of the predictors on mortality are expected to materialize over time, we also conducted analyses with time lags. A total of 3 time lag models (each with a 5-year lag) were presented. The first model compares total mortality in 1985 as a function of the independent measures from 1980; the second compares mortality in 1990 with predictors from 1985, and the third compares mortality from 1995 with predictors from 1990. 
Table 1. Correlations between Primary Care, Specialty Care, Income Inequity, and Standardized Mortality, US States 1980-1995

\begin{tabular}{|c|c|c|c|c|}
\hline & \multicolumn{4}{|c|}{$\begin{array}{l}\text { Age-Standardized Deaths per 100,000 } \\
\text { Population from All Causes }\end{array}$} \\
\hline & 1980 & 1985 & 1990 & 1995 \\
\hline \multicolumn{5}{|l|}{ Gini Coefficent } \\
\hline Same period & $.42^{\ddagger}$ & $.39^{\ddagger}$ & $.55^{\ddagger}$ & \multirow[t]{2}{*}{$.28^{\dagger}$} \\
\hline Prior period & $.46^{\ddagger}$ & $.48^{\ddagger}$ & $.55^{\ddagger}$ & \\
\hline \multicolumn{5}{|l|}{ Robin Hood } \\
\hline Same period & $.42^{\ddagger}$ & $.42^{\ddagger}$ & $.48^{\ddagger}$ & \multirow[t]{2}{*}{$.25^{*}$} \\
\hline Prior period & $.46^{\ddagger}$ & $.51^{\ddagger}$ & $.52^{\ddagger}$ & \\
\hline \multicolumn{5}{|l|}{ Specialty Care } \\
\hline Same period & .13 & .02 & -.09 & \multirow[t]{2}{*}{-.13} \\
\hline Prior period & -.11 & -.09 & -.18 & \\
\hline \multicolumn{5}{|l|}{ Primary Care } \\
\hline Same period & $.30^{\dagger}$ & -.18 & $-.26^{*}$ & \multirow[t]{2}{*}{$-.29^{\dagger}$} \\
\hline Prior period & $-.30^{\dagger}$ & $-.25^{\star}$ & $-.34^{\dagger}$ & \\
\hline \multicolumn{5}{|l|}{ Family Medicine } \\
\hline Same period & $-.47^{\ddagger}$ & $-.35^{\ddagger}$ & $-.32^{\dagger}$ & \multirow[t]{2}{*}{$-.27^{*}$} \\
\hline Prior period & $-.50^{\ddagger}$ & $-.31^{\dagger}$ & $-.25^{*}$ & \\
\hline \multicolumn{5}{|c|}{ Internal Medicine } \\
\hline Same period & -.10 & -.03 & -.11 & \multirow[t]{2}{*}{-.18} \\
\hline Prior period & -.09 & -.11 & -.19 & \\
\hline \multicolumn{5}{|l|}{ Pediatrics } \\
\hline Same period & -.08 & -.01 & -.07 & \multirow[t]{2}{*}{-.05} \\
\hline Prior period & -.07 & -.07 & -.16 & \\
\hline $\begin{array}{l}{ }^{*} P<.1 \\
{ }^{\dagger} P<.05 \\
{ }^{\ddagger} P<.01 \\
{ }_{\mathrm{n}}=50\end{array}$ & & & & \\
\hline
\end{tabular}

\section{Results}

\section{Bivariate Analyses}

Table 1 presents Pearson correlations between mean income inequality (Gini coefficient and Robin Hood Index), primary care, primary care specialty physicians, specialty physicians, and allcause mortality for each state for the periods 1980, 1985, 1990, and 1995. Both the Gini coefficient and the Robin Hood Index were statistically significantly associated with state all-cause mortality during every period $(P<.01$ for all measures, except the Gini coefficient in 1995 , where $P<.05$ ). The magnitude of the association does not show a clear trend. The highest correlations were seen in 1990, whereas the lowest correlations were observed in 1995. Five-year lagged income inequality measures were likewise significantly correlated with mortality but the magnitude of the association increased each period from 0.46 in 1985 to 0.55 in $1995(P<$ .01 for each period).

Primary care was negatively associated with mortality in $1980(P<.01), 1985$ (not significant), $1990(P<.1)$, and $1995 P<.01)$. Five-year lagged primary care measures showed a stronger negative association than contemporary primary care measures. The primary care subspecialty of general practice was likewise negatively associated with allcause mortality for each period. The strength of the association decreased with each period, and statistical significance declined to $90 \%$ in 1995. Lagged general practice measures showed a similar pattern. Neither contemporary nor lagged measures of internal medicine, general pediatricians, or specialty care physicians were significantly associated with mortality at any period.

\section{Multivariate Analyses}

Table 2 presents the weighted regression coefficients of primary care, income inequality, and specialty care on all-cause mortality. Four columns are presented, 1 for each 5-year period. The results show that income inequality and specialty care were strongly associated with higher mortality, while primary care was associated with lower mortality in each period.

Each period shows essentially the same pattern in terms of the significance direction and magnitude of the association between the explanatory variables and mortality. In ordinary least-squares regression, the $\beta$-coefficient estimates the effect of a 1-unit increase in the independent variable on the dependent variable (mortality). For example, in 1995, a 1-unit increase in the Gini coefficient (ie, income redistribution favoring the rich) was associated with as many as 719 deaths per 100,000, whereas an increase of 1 primary care physician per 10,000 persons was associated with a reduction of 35 deaths per 100,000. An increase of 1 specialty physician per 10,000 population was associated with approximately 15 additional deaths per 100,000 .

The square of the multiple correlation coefficient $\left(\mathrm{R}^{2}\right)$ is a measure of the proportion of the variance in the dependent variable explained by all the independent variables in the model. All $\mathrm{R}^{2}$ values reported here are adjusted for the number of covariates in each model. ${ }^{30}$ The adjusted $\mathrm{R}^{2}$ values (ranging from 0.27 to 0.35 ) indicate that the models 
Table 2. Regression Coefficients of Primary Care, Specialty Care, and Income Inequity on Standardized Mortality, US States 1980-1995

\begin{tabular}{|c|c|c|c|c|}
\hline & \multicolumn{4}{|c|}{ Age-Standardized Deaths per 100,000 Population from All Causes } \\
\hline & 1980 & 1985 & 1990 & 1995 \\
\hline \multirow[t]{2}{*}{ Intercept } & 463.02 & 478.09 & 286.37 & 554.65 \\
\hline & {$[205.22]$} & {$[168.10]$} & {$[174.85]$} & [44.11] \\
\hline \multirow[t]{3}{*}{ Gini Coefficient } & 1249.12 & 1003.57 & 1324.50 & 719.14 \\
\hline & [488.89] & {$[385.87]$} & {$[380.33]$} & [342.59] \\
\hline & $\left(2.56^{\ddagger}\right)$ & $\left(2.60^{\ddagger}\right)$ & $\left(3.48^{\ddagger}\right)$ & $\left(2.10^{\dagger}\right)$ \\
\hline \multirow[t]{3}{*}{ Primary Care } & -37.69 & -33.80 & -25.99 & -35.53 \\
\hline & {$[13.85]$} & {$[12.48]$} & {$[11.90]$} & [11.25] \\
\hline & $\left(-2.72^{\ddagger}\right)$ & $\left(-2.71^{\ddagger}\right)$ & $\left(-2.19^{\dagger}\right)$ & $\left(-3.16^{\ddagger}\right)$ \\
\hline \multirow[t]{3}{*}{ Specialty Care } & 15.78 & 16.46 & 10.56 & 14.98 \\
\hline & {$[7.03]$} & {$[6.52]$} & {$[6.20]$} & {$[6.79]$} \\
\hline & $\left(2.24^{\dagger}\right)$ & $\left(2.53^{\dagger}\right)$ & $\left(1.70^{*}\right)$ & $\left(2.21^{\dagger}\right)$ \\
\hline $\mathrm{R}^{2}$ & .30 & .27 & .35 & .28 \\
\hline Adjusted $\mathrm{R}^{2}$ & .25 & .22 & .31 & .23 \\
\hline F Ratio & $6.46^{\ddagger}$ & $5.55^{\ddagger}$ & $8.28^{\ddagger}$ & $5.99^{\ddagger}$ \\
\hline
\end{tabular}

Parameter estimates on top, standard errors in brackets, $t$ values in parentheses.

* $P<.1$

${ }^{+} P<.05$

${ }^{\ddagger} P<.01$

$\mathrm{n}=50$

explain only about $30 \%$ of variance in age-adjusted total mortality.

Table 3 is similar to Table 2, except that primary care was divided into its 3 specialty components (family medicine, internal medicine, and general pediatrics). In weighted multiple regressions for the 4 time periods, the Gini coefficient continued to be positively associated with all-cause mortality $(P<$ .05 for all periods, except in 1995, when the statistical significance fell to the $P<.1$ level). The magnitude of the regression coefficient was reduced, however. For example, in 1995, a 1-unit increase in the Gini coefficient was associated with an additional 657 deaths per 100,000, as opposed to 719 in the previous table.

Among the primary care specialties included in the model, only family medicine was statistically significant for all 4 periods $(P<.01)$. An increase of 1 family medicine physician per 10,000 persons was associated with a decrease of 71 deaths per 100,000 in 1980 and 39 deaths per 100,000 in 1995. The internal medicine primary care specialty was statistically significant only in $1995(P<.05)$ : an increase of 1 general internist per 10,000 persons was associated with a decrease of 30 deaths per 100,000 in 1995 . However, the number of general pediatricians was not significantly associated with mortal- ity. As in the previous table, specialty physicians were not significantly associated with mortality during any period. The adjusted $\mathrm{R}^{2}$ measures range from 0.30 to 0.43 , indicating that the models are improved over those presented in Table 2. Each explains more than $30 \%$ of variance in age-adjusted total mortality.

Because the effect of income inequality and primary care on mortality is expected to manifest over time, Table 4 presents results of weighted regressions of time-lagged primary care, specialty care, and income inequality measures on mortality. We also tested the effects of 2 different income inequality measures: the Robin Hood index and the Gini coefficient.

Each column presents the regression of the 5 -year time-lagged predictors on mortality rates. Separate models compare the effect of the Robin Hood index with that of the Gini coefficient.

In each of the periods tested, the relationship is similar: both time-lagged income inequality measures were positively associated with mortality $(P<$ .01 for both measures at each period). The magnitude of the $\beta$-coefficient for the Robin Hood index was consistent at about 18 for all periods, whereas the magnitude of the Gini coefficient increased from 1340 in 1985 to 1448 in 1995. 
Table 3. Regression Coefficients of Primary Care Subspecialties, Specialty Care, and Income Inequity on Standardized Mortality, US States 1980-1995

\begin{tabular}{|c|c|c|c|c|}
\hline & \multicolumn{4}{|c|}{ Age-Standardized Deaths per 100,000 Population from All Causes } \\
\hline & 1980 & 1985 & 1990 & 1995 \\
\hline \multirow[t]{2}{*}{ Intercept } & 751.19 & 613.25 & 442.69 & 632.56 \\
\hline & {$[213.11]$} & {$[184.90]$} & {$[204.43]$} & {$[186.78]$} \\
\hline \multirow[t]{3}{*}{ Gini Coefficent } & 954.55 & 950.42 & 1204.1 & 657.30 \\
\hline & {$[466.39]$} & {$[386.51]$} & [391.2] & {$[364.39]$} \\
\hline & $\left(2.05^{+}\right)$ & $\left(2.46^{\dagger}\right)$ & $\left(3.08^{\ddagger}\right)$ & $\left(1.80^{*}\right)$ \\
\hline \multirow[t]{3}{*}{ Specialty Care } & -1.73 & 3.55 & 1.27 & 5.48 \\
\hline & {$[10.22]$} & {$[9.89]$} & {$[9.82]$} & {$[11.20]$} \\
\hline & $(-.17)$ & $(.36)$ & $(.13)$ & $(.49)$ \\
\hline \multirow[t]{3}{*}{ Family Medicine } & -70.94 & -50.69 & -41.10 & -38.69 \\
\hline & {$[16.60]$} & {$[15.68]$} & {$[15.42]$} & [14.59] \\
\hline & $\left(-4.27^{\ddagger}\right)$ & $\left(-3.23^{\ddagger}\right)$ & $\left(-2.67^{\ddagger}\right)$ & $\left(-2.65^{\ddagger}\right)$ \\
\hline \multirow[t]{3}{*}{ Internal Medicine } & 7.80 & -12.36 & -8.56 & -29.82 \\
\hline & [19.98] & [19.31] & {$[17.52]$} & [14.69] \\
\hline & $(.39)$ & $(-.64)$ & $(-.49)$ & $\left(-2.03^{\dagger}\right)$ \\
\hline \multirow[t]{3}{*}{ Pediatrics } & -72.28 & -27.69 & -32.43 & .43 \\
\hline & {$[58.68]$} & {$[52.60]$} & {$[48.76]$} & {$[38.02]$} \\
\hline & $(-1.23)$ & $(-.53)$ & $(-.67)$ & $(.01)$ \\
\hline $\mathrm{R}^{2}$ & .43 & .32 & .38 & .30 \\
\hline Adjusted $\mathrm{R}^{2}$ & .36 & .24 & .31 & .22 \\
\hline F Ratio & $6.53^{\ddagger}$ & $4.09^{\ddagger}$ & $5.47^{\ddagger}$ & $3.78^{\ddagger}$ \\
\hline
\end{tabular}

Parameter estimates on top, standard errors in brackets, $t$ values in parentheses.

${ }^{*} P<.1$

$+P<.05$

${ }^{\ddagger} P<.01$

$\mathrm{n}=50$

The time-lagged primary care measure exhibited a consistent pattern as well. It was negatively associated with mortality at each period $(P<.05$ for all models). The magnitude of the primary care regression coefficient did not significantly differ based on the income inequality measure used in the model. Time-lagged primary care measures were associated with a decrease of about 40 deaths per 1000,000 in 1985 to less than 30 deaths per 100,000 for in 1995. The magnitude of this association was similar to that of the contemporary primary care measure.

We also conducted time-lagged analyses examining the influence of primary care specialties on mortality (results not shown but available on request). As with contemporaneous analysis, only family medicine was statistically significant for all 4 periods $(P<.01)$. An increase of 1 family medicine physician per 10,000 persons was associated with a decrease of about 70 deaths per 100,000. The internal medicine and pediatrics primary care special- ties were inversely but not statistically significantly associated with mortality $(P>.05)$.

Time-lagged specialty care was positively associated with mortality in 1985 and $1990(P<.05)$, but statistical significance declined to the $90 \%$ level in 1995. The magnitude of the regression coefficient was similar for each income inequality measure at each period and declined from approximately 17 in 1985 to approximately 10 in 1995 .

The adjusted $\mathrm{R}^{2}$ measures range from 0.34 to 0.39 , indicating that the models explain more than $30 \%$ of the variance in age-adjusted total mortality. There was no clear difference between adjusted $\mathrm{R}^{2}$ values for models using the Gini coefficient versus those using the Robin Hood index.

\section{Discussion}

Our study confirms earlier findings that, among US states, income inequality is associated with poorer health. ${ }^{8,26,35,36}$ Income inequality remained a sig- 
Table 4. Regression Coefficients of Primary Care, Specialty Care, and Income Inequity on Standardized Mortality, US States 1980-1995

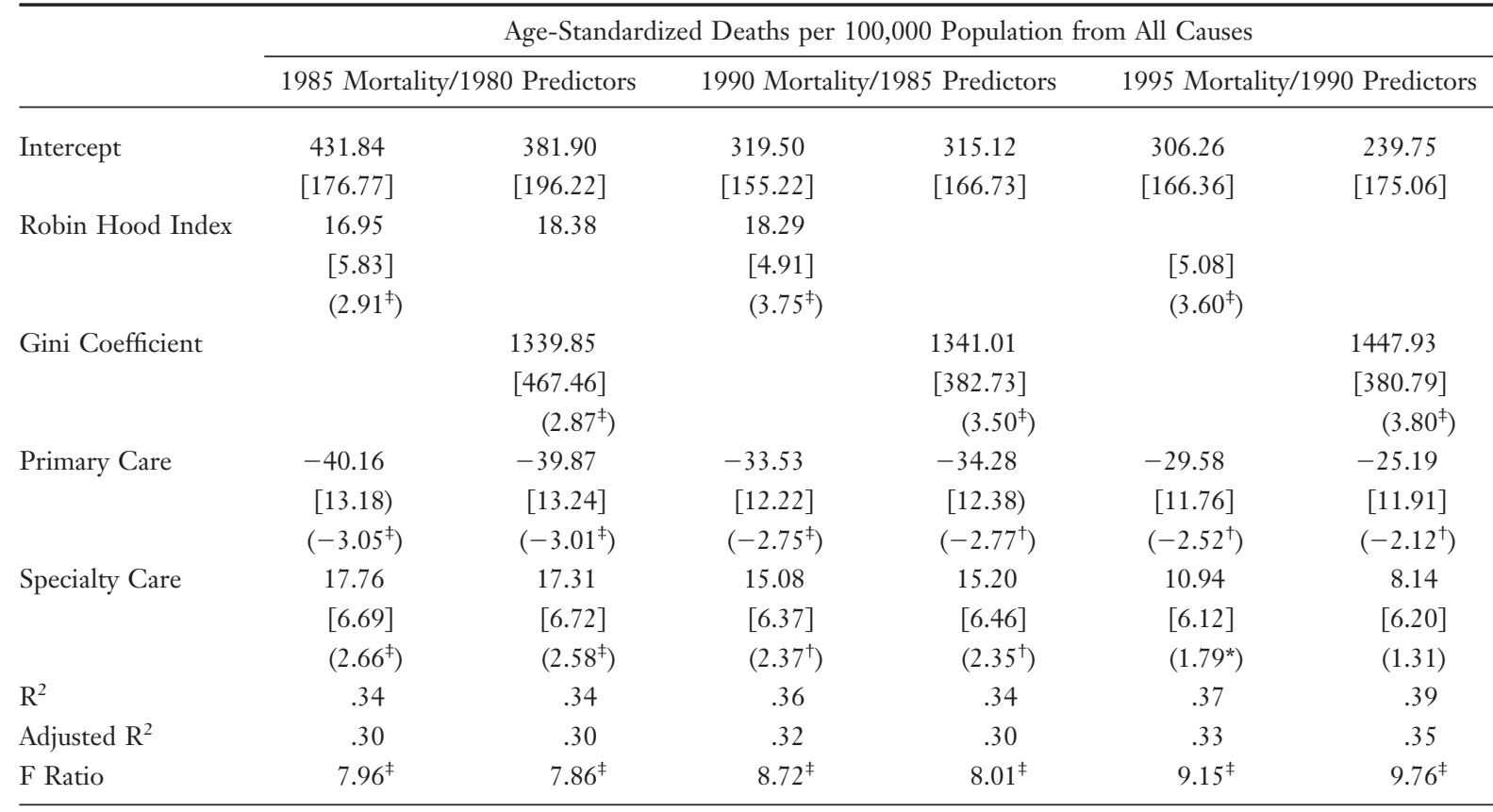

Parameter estimates on top, standard errors in brackets, $t$ values in parentheses.

${ }^{*} P<.1$

${ }^{\dagger} P<.05$

${ }^{\ddagger} P<.01$

$\mathrm{n}=50$

nificant correlate of mortality, even after accounting for the effect of primary and specialist care. The robustness of this association was confirmed by testing 2 measures of income inequality (the Gini coefficient and the Robin Hood Index) and by using time-lagged income inequality measures. Both income inequality measures were significantly associated with greater mortality in both contemporaneous and time-lagged models. Incidentally, total income was not significantly related to mortality.

We also found that primary care, specifically family medicine, was significantly associated with state-level mortality over a 20 -year period and that time-lagged primary care variables predicted mortality rates. Although we cannot test causality with this study design, the fact that time-lagged measures of primary care were more strongly associated with mortality than contemporaneous primary care measures suggests a relationship between primary care structure and later mortality. Because mortality is significantly and inversely related to life expectancy, a reduction in mortality means a corresponding increase in life expectancy. Using 1990 data, we estimate an increase of 1 primary care doctor per 10,000 persons was associated with an increase of 0.67 year of life expectancy $(t=3.531$, $P<.001)$. On the other hand, deterioration of income distribution (a $1 \%$ increase in income disparity between the rich and the poor) was associated with reduction of 0.26 year of life expectancy $(t=-2.921, P<.01)$ (test results available on request).

The significant inverse relationship between primary care, particularly family medicine, and mortality persists after including additional measures of social status including health insurance, total per capita income, education, poverty, and minority (results not shown but available on request). However, income inequality is no longer significantly associated with mortality after including the additional measures of social status.

Primary care specialties differed in their impact on mortality. The strongest effect was seen for family medicine physicians. This is probably because family medicine practitioners are likely to be most accessible to the patients particularly vulnerable populations, and they take care of the most essential health needs of the population. They also 
tend to make up a relatively higher proportion of primary care physicians in the United States. Internal medicine was not generally associated with mortality (neither an increase nor a reduction in mortality), possibly because of the relatively smaller proportion of primary care physicians who are specialized in internal medicine. Finally, regarding pediatricians, there are 2 explanations for the lack of a significant effect (ie, increasing the supply of pediatricians does not reduce mortality). First, pediatricians represent only about a small percentage of the primary care labor force. Second, it is likely that because the health outcome (all-cause mortality) occurs less frequently among children than among adults, the impact of pediatricians was not detected. Although pediatricians are an important source of primary care for children and adolescents, their impact might be better captured by an outcome measure that reflects the burden of illness faced by this subpopulation (eg, age- or causespecific health outcomes).

The third finding is that contemporaneous and time-lagged measures of specialty care were either not associated with mortality or were associated with worse health outcomes at each time period. This finding is consistent with earlier analyses. ${ }^{14,28,37}$

Although our findings seem to be robust, there are several limitations to this study. First, in addition to the primary care specialties identified, other health care professionals (eg, osteopathic physicians and nonphysician providers) also provide primary care services. Data limitation precluded us from including these in the analyses.

Second, the mere presence of more primary care physicians per population does not assure that more persons in the population are exposed to primary care or that the delivery of primary care will produce better health outcomes at the individual level. To draw this conclusion would risk committing an ecological fallacy. However, several lines of evidence help us to interpret the effects of statelevel primary care on population health.

Because of data limitations, there is currently no way to determine whether states with higher primary care physician ratio are states in which access to and receipt of primary care services is better than in other states with lower primary care physician/ population ratios. However, there is an increasing body of research demonstrating the beneficial impact of primary care at the ecological level.
The first such evidence is derived from ecological studies conducted in a dozen Western industrialized countries. In these studies, the strength of the national primary care system was assessed by scoring 7 features of the primary care infrastructure (including primary care physician/population ratios) and 6 characteristics of primary care practice (delivery). In both analyses, those countries with weak primary care infrastructures had much lower scores for access to and quality of primary care practice. ${ }^{11,12}$

The second line of evidence comes from ecological studies of the relationship between primary care personnel and population ratios and various types of health outcomes. Both Shi and colleagues $^{13,14,16,28}$ and Farmer et $\mathrm{al}^{38}$ found better health outcomes in states with higher primary care/ physician ratios. Parchman and Culler ${ }^{39}$ demonstrated that geographic areas with more family and general physicians per population had lower hospitalization rates for conditions that should be preventable with good primary care; the same was not the case for general internists or general pediatricians.

The effect of primary care-to-population ratios on health outcomes may occur, at least in part, because physicians trained in primary care are more likely to achieve cardinal primary care functions with known relationships to improved health outcomes. ${ }^{40,41}$ Exercise of these functions can also lead to improved functioning of the health system at large because strong primary care not only means more prevention, but also better referral, coordination, and continuity of care. ${ }^{42,43}$

Studies on the individual level also provide evidence of the beneficial impact of primary care on health outcomes. Shea et $\mathrm{al}^{44}$ used a case-control approach to demonstrate the impact of having a primary care physician. Men appearing at an emergency department in a large metropolitan area were characterized as having complications of hypertension or as having another condition and uncomplicated hypertension. Those with complications of hypertension were much less likely to have a source of primary care than men whose hypertension was an incidental finding, even while controlling for other factors such as insurance coverage. Franks \& Fiscella, ${ }^{45}$ using nationally representative survey data, showed that adult respondents who reported a primary care physician rather than a specialist as their regular source of care had lower subsequent 
mortality and lower annual health care costs, after controlling for differences in demographic characteristics, health insurance status, health perceptions, reported diagnoses, and smoking status.

Moreover, it may be that both equality in the distribution of income and primary care orientation of a health services system are part of a common underlying social and political process of allocating resources, which may be the ultimate "causal agent." There is preliminary international evidence that a country's political context may help determine social policies regarding resource distribution $^{46}$ and that some policies, such as the type of health care financing, may influence health outcomes. ${ }^{47}$ To our knowledge, such studies have not yet been extended to examine US states.

\section{Conclusions}

We have argued elsewhere that improvement in health of populations is likely to require a multipronged approach that addresses socioeconomic and behavioral determinants of health and strengthens certain aspects of health services. ${ }^{16}$ The literature on income inequality and health has, by and large, not included serious examination of the role of health services on mitigating the health burden imposed by income and other social inequalities. This study provides further evidence that improving primary care, particularly family medicine, is a possible approach to mitigate at least some of the deleterious health effects of social inequalities. The fact that primary care, particularly family medicine, was found to be associated with better health outcome suggests that improving the ratio of primary care (especially family medicine physicians) to population could improve health outcomes, even in states with serious health inequalities.

Improving primary care is also justified by an examination of the current physician supply. Overall, the United States still has a serious imbalance between the production of primary care physicians and those in other specialties. ${ }^{48-50}$ Compared with most other industrialized countries, the United States has a low proportion of physicians who are primary care generalists and a correspondingly high proportion who are specialists. ${ }^{50}$ International comparisons suggest that industrialized nations that promote primary care over specialty care achieve better health status and lower overall costs than those who do not. ${ }^{51,52}$
Finally, improving primary care, in particular family medicine, is a potentially viable recommendation for health policy-makers in the United States, who would like to reduce health inequalities but who often lack the political power or mandate to affect factors outside the health sector. Such an approach could be justified not only because of the evidence of the impact of primary care on population health, but also because of emerging evidence that primary care may also provide an important counter-balance to at least some health-damaging environmental conditions, such as income inequality. Indeed, international evidence suggests that nations embracing primary care are also probably more egalitarian. Therefore, in the United States, advancing primary care may well serve as a viable strategy to reducing inequities, in addition to improving health.

\section{References}

1. Gravelle H. How much of the relation between population mortality and unequal distribution of income is statistical artifact? In: Kawachi I, Kennedy B, Wilkinson RG. The society and population health reader. New York: The New Press, 1999:99-104

2. Judge K. Income distribution and life expectancy: a critical appraisal. BMJ 1995;311:1282-5.

3. Kawachi I, Kennedy B, Wilkinson R, editors. The society and population health reader. Volume 1: income inequality and health. New York: The New Press, 1999.

4. Wilkinson R. Unhealthy societies: the afflictions of inequality. London: Routledge, 1996.

5. Mellor JM, Milyo J. Reexamining the evidence of an ecological association between income inequality and health. J Health Polit Policy Law 2001;26:487522.

6. Wilkinson R. Socioeconomic determinants of health: health inequalities: relative or absolute material standards? BMJ 1997;314:591-5.

7. Judge K, Paterson I. Poverty, income inequality and health. Aukland, New Zealand: New Zealand Treasury, 2002.

8. Lochner K, Pamuk E, Makuc D, Kennedy B, Kawachi I. State-level income inequality and individual mortality risk: a prospective, multilevel study. Am J Public Health 2001;91:385-91.

9. Lynch J, Smith GD, Hillemeier M, Shaw M, Raghunathan T, Kaplan G. Income inequality, the psychosocial environment, and health: comparisons of wealthy countries. Lancet 2001;358:194-200.

10. Starfield B. Primary care visits and health policy [editorial]. CMAJ 1998;159:795-6. 
11. Starfield B. Is primary care essential? Lancet 1994; 344:1129-33.

12. Starfield B, Shi L. Policy relevant determinants of health: an international perspective. Health Policy 2002;60:201-18.

13. Shi L. The relation between primary care and life chances. J Health Care Poor Underserved 1992;3: 321-35.

14. Shi L. Primary care, specialty care, and life chances. Int J Health Serv 1994;24:431-58.

15. Shi L. Balancing primary versus specialty care. J R Soc Med 1995;88:428-32.

16. Shi L, Starfield B, Kennedy B, Kawachi I. Income inequality, primary care, and health indicators. J Fam Pract 1999;48:275-84.

17. US Department of Commerce and the Census Bureau. 1992-1998. Statistical abstracts of the United States. Washington, DC: US Government Printing Office.

18. US Department of Health and Human Services, National Center for Health Statistics. Health, United States. 1985-1996. Washington, DC: US Department of Health and Human Services.

19. Klein RJ, Hawk SA. Health status indicators: definitions and national data. Statisital Notes Series. Hyattsville, MD: National Center for Health Statistics, Centers for Disease Control and Prevention, U.S. Department of Health and Human Services, 1992:1-8. DHHS publication no. (PHS) 92-1237. Available at: URL:

20. AMA Physician Master file. Chicago: American Medical Association, 1998.

21. Bergner M. Measurement of health status. Medical Care 1985;23:696-704.

22. Rice DP. Health status and national health priorities. West J Med 1991;154:294-302.

23. Friede A, Reid JA, Ory HW. CDC Wonder: A comprehensive on-line public health information system of the Centers for Disease Control and Prevention. Am J Public Health 1983;83:1289-94.

24. Coulter P. Measuring inequality: a methodological handbook. Boulder: Westview Press, 1989.

25. Welniak E. Software. Gini coefficient calculator. Washington DC: US Census Bureau, 1988.

26. Kennedy BP, Kawachi I, Prothrow-Stith D. Income distribution and mortality: cross sectional ecological study of the Robin Hood index in the United States. BMJ 1996;312:1004-7.

27. Starfield B. Primary care in the United States. Int J Health Serv 1996;16:179-98.

28. Shi L, Starfield B. Primary care, income inequality, and self-rated health in the United States: a mixedlevel analysis. Int J Health Serv 2000;30:541-55.

29. Blakely T, Kawachi I. What is the difference between controlling for mean versus median income in analyses of income inequality? J Epidemiol Community Health 2001;55:352-3.
30. Pedhazur EJ. Multiple regression in behavioral research. New York: Holt, Rinehart \& Winston, 1973.

31. Susser M. The logic in ecological. I: the logic of analysis. Am J Public Health 1994;84:825-9.

32. Schwartz S. The fallacy of the ecological fallacy: the potential misuse of a concept and the consequences. Am J Public Health 1994;84:819-24.

33. Hadley J. More medical care, better health? Washington, DC: The Urban Institute Press, 1982.

34. Rothman KJ. Modern epidemiology. Boston: Little, Brown, 1986.

35. Blakely TA, Lochner K, Kawachi I. Metropolitan area income inequality and self-rated health-a multi-level study. Soc Sci Med 2002;54:65-77.

36. Kennedy BP, Kawachi I, Glass R, Prothrow-Stith D. Income distribution, socioeconomic status, and self rated health in the United States: multilevel analysis. BMJ 1998;317:917-21.

37. Shi L, Starfield B. The effect of primary care physician supply and income inequality on mortality among blacks and whites in US metropolitan areas. Am J Public Health 2001;91:1246-50.

38. Farmer FL, Stokes CS, Fisher RH. Poverty, primary care and age-specific mortality. J Rural Health 1991; 7:153-69.

39. Parchman M, Culler S. Primary care physicians and avoidable hospitalization. J Fam Pract 1994;39: 123-8.

40. Rosenblatt RA, Hart L, Baldwin LM, Chan L, Schneeweiss $\mathrm{R}$. The generalist role of specialty physicians: is there a hidden system of primary care? JAMA 1998;279:1364-70.

41. Weiner JP, Starfield B. Measurement of the primary care roles of office-based physicians. Am J Public Health 1983;73:666-71.

42. Casanova C, Colomer C, Starfield B. Pediatric hospitalization due to ambulatory care-sensitive conditions in Valencia (Spain). Int J Qual Health Care 1996;8:51-9.

43. Casanova C, Starfield B. Hospitalizations of children and access to primary care: a cross-national comparison. Int J Health Serv 1995;25:283-94.

44. Shea S, Misra D, Ehrlich MH, Field L, Frances C. Predisposing factors for severe, uncontrolled hypertension in an inner-city minority population. N Engl J Med 1992;327:776-81.

45. Franks P, Fiscella K. Primary care physicians and specialists as personal physicians. Health care expenditures and mortality experience. J Fam Pract 1998; 47:105-9.

46. Navarro V, Shi L. The political context of social inequalities and health. Soc Sci Med 2001;52:48191.

47. Elola J, Daponte A, Navarro V. Health indicators and the organization of health care systems in Western Europe. Am J Public Health 1995;85:1397-401. 
48. Graduate Medical Education National Advisory Committee. Summary Report to the Secretary, Department of Health and Human Services (DHHS), Vol. 1. Hyattsville, MD: Health Resources Administration, 1980.

49. Politzer RM, Harris DL, Gaston MH, Mullan F. Primary care physician supply and the medically underserved. JAMA 1991;266:104-9.
50. Schroeder SA. Physician supply and the U.S. medical marketplace. Health Aff (Millwood) 1992:235-43.

51. Shi L. Health care spending, delivery, and outcome in developed countries: a cross-national comparison. Am J Med Qual 1997;12:83-93.

52. Starfield B. Primary care: balancing health needs, services and technology. New York: Oxford University Press, 1998. 